\title{
Risk Stratification of Submassive Pulmonary Embolism: The Role of Chest Computed Tomography as an Alternative to Echocardiography
}

\author{
Won Young Kim, Shin Ahn and Choong Wook Lee \\ University of Ulsan College of Medicine/Asan Medical Center
}

Korea

\section{Introduction}

Acute pulmonary embolism (PE) is a common and potentially fatal disease (Goldhaber et al., 1999). The most frequent cause of death within 30 days is right ventricular (RV) failure (Goldhaber \& Elliott, 2003). Rapid risk stratification is paramount for identifying high-risk patients and for helping to select the appropriate treatment strategy. According to European guidelines (Torbicki et al., 2008), high-risk PE (formerly 'massive' PE) implies the presence of shock or hemodynamic instability (mortality >15\%) (Goldhaber et al., 1999). Non highrisk PE can be further stratified by the presence of markers of RV dysfunction and/or myocardial injury as intermediate- and low-risk PE. Intermediate-risk PE (formerly 'submassive' PE) is diagnosed by the presence of at least one marker of RV dysfunction or myocardial injury. Low-risk PE (formerly 'non-massive' PE) is diagnosed when RV dysfunction markers are negative (mortality <1\%). Reperfusion therapy, including thrombolysis or surgical embolectomy, is indicated for patients with high-risk PE. However, the risks and benefits of reperfusion therapy for patients with intermediate risk PE are less clear. Based on pathophysiological knowledge of the impact of RV dysfunction on acute PE, risk stratification is based on imaging modalities for the visualization of RV dysfunction. Therefore, echocardiographic assessment of RV dysfunction in acute PE may predict early mortality, and may guide decisions regarding reperfusion therapy (Grifoni et al., 2000; Kucher et al., 2005). Echocardiography, however, is time-consuming, operator-dependent, and not always available in an emergency situation, and echocardiographic criteria for assessing RV have not yet been determined. The development of narrow collimation, multi-detector row computed tomography (CT) imaging, and modern workstations for image postprocessing and analysis have made CT pulmonary angiography the modality of choice for the assessment of patients with pulmonary emboli (Ghaye et al., 2006; Schoepf \& Costello, 2004). At times, CT is more rapidly accessible in emergency settings, and is more widely available than echocardiography. CT enables the direct visualization of emboli and provides information about cardiac morphology. CT findings, including RV enlargement, the ratio of RV diameter to the diameter of the left ventricle (LV) (RV/LV ratio), interventricular septal bowing, and pulmonary vascular obstruction score, have been associated with early mortality and clinical outcomes (Araoz et al., 2003; Collomb et al., 2003; Coutance et al., 2011; Ghuysen et al., 2005; 
Jimenez et al., 2010; Lu et al., 2009; Qanadli et al., 2001; Sanchez et al., 2008; Schoepf \& Costello, 2004; van der Meer et al., 2005; Wu et al., 2004).

This chapter will focus on recent studies comparing CT and echocardiographic findings of RV dysfunction. The data obtained in these trials provide the background for emerging risk stratification algorithms, which we hope will lead to the use of chest CT as an alternative to echocardiography in the successful identification of RV dysfunction.

\section{Echocardiographic assessment of right ventricular dysfunction}

Transthoracic echocardiography is a noninvasive tool that can be easily utilized at the bedside, even in hemodynamically compromised patients. It can help diagnose conditions that mimic acute PE but are treated differently, such as acute myocardial infarction, aortic dissection, and pericardial tamponade. Although echocardiography is not recommended for the diagnosis of PE, it can detect or exclude RV dysfunction. Moreover, echocardiography is an important tool for risk stratification in patients with PE because RV dysfunction on an echocardiogram is a powerful and independent predictor of mortality (Ribeiro et al., 1997; Torbicki et al., 2003). Echocardiographic findings suggesting RV dysfunction have been reported to occur in at least $25 \%$ of patients with PE (Kreit, 2004). A meta-analysis found that patients with echocardiographic signs of RV dysfunction were at greater than two-fold higher risk of PE-related mortality than patients without signs of RV dysfunction (ten Wolde et al., 2004). Importantly, patients with normal echocardiographic findings had excellent outcomes, with in-hospital PE-related mortality rates $<1 \%$ in most of the reported series. A recent systemic review (Fremont et al., 2008) identified five studies that evaluated the prognostic role of echocardiography in diagnosing RV dysfunction. The unadjusted relative risk of RV dysfunction for predicting death was 2.5 (95\% CI 1.2-5.5).

Echocardiography, however, has limitations, including restricted availability and relatively high cost. Moreover, in some patients, including those with chronic obstructive pulmonary disease or morbid obesity, it is difficult to adequately image the RV free wall with a transthoracic approach. More importantly, the lack of a clear echocardiographic definition of RV dysfunction is problematic (ten Wolde et al., 2004). A meta-analysis of eight studies that compared the impact of RV dysfunction measured by echocardiography and CT found that the presence of echocardiographically determined RV dysfunction in patients with submassive PE was associated with increased short-term mortality (OR 2.36, 95\% CI: 1.3-43), but that corresponding pooled negative and positive likelihood ratios independent of death rates were unsatisfactory for clinical usefulness in risk stratification (Coutance et al., 2011). Unfortunately, the echocardiographic criteria of RV dysfunction differ among published studies and have included RV dilatation, hypokinesis, increased RV/LV diameter ratio and increased velocity of the tricuspid regurgitation jet. Thus, since there is no universal echocardiographic definition of RV dysfunction, only a completely normal result should be considered as defining low-risk PE. This is particularly important because, in some of trials, echocardiographic signs of RV pressure overload alone (such as increased tricuspid insufficiency peak gradient and decreased acceleration time of RV ejection) were considered sufficient to classify a patient as having RV dysfunction.

\subsection{Echocardiographic findings of right ventricular dysfunction}

$\mathrm{RV}$ dysfunction is diagnosed by the presence of RV dilatation, defined as a RV/LV enddiastolic dimension ratio $>0.6$ on a parasternal long-axis view or $>0.9$ on a four-chamber 
view (Fig. 1); as RV systolic free wall hypokinesis (McConnell sign); or as systolic pulmonary arterial hypertension, defined as a tricuspid regurgitant velocity $>2.6 \mathrm{~m} / \mathrm{s}$ (Goldhaber, 2002). Indirect signs of RV pressure overload include a flattened interventricular septum, paradoxical systolic motion of the interventricular septum toward the LV, and a dilated inferior vena cava with reduced respiratory variability (Table 1 ).

Signs of RV dysfunction have been found in $40-70 \%$ of patients with PE, and numerous studies have demonstrated that echocardiography is a useful tool for estimating the prognosis of normotensive patients with acute PE (Goldhaber et al., 1999; Ribeiro et al., 1997; Grifoni et al., 2001). A recent meta-analysis found that echocardiographic evidence of RV dysfunction was associated with a significantly elevated risk of death during the acute phase of PE (OR, 2.5; 95\% CI, 1.2-5.5\%) (Sanchez et al., 2008). However, since large populations of patients with signs of RV dysfunction have low mortality rates, echocardiographic detection of RV dysfunction alone does not justify more aggressive treatment strategies (Goldhaber et al., 1999; Konstantinides, 2008). More importantly, definitions of RV dysfunction differed greatly among these studies, and patients with chronic obstructive pulmonary disease were not excluded (Jimenez et al., 2007). In addition, it is difficult to differentiate chronic from acute RV overload based on standardized criteria (e.g. RV free wall thickness $>6 \mathrm{~mm}$ or tricuspid valve regurgitation jet velocity $>2.6 \mathrm{~m} / \mathrm{sec}$ ).

\subsubsection{Echocardiographic $R V / L V$ ratio}

A retrospective study of 950 patients showed that the echocardiographic RV/LV ratio was prognostic in the evaluation of $\mathrm{PE}$, with a critical cutoff for prediction of in-hospital mortality of 0.9 (Fremont et al., 2008). Echocardiograms were electrocardiogram (ECG)gated to allow end-diastolic diameter measurement on the $\mathrm{R}$ wave. The minor axes of the $\mathrm{RV}$ and LV were measured in apical 4-chamber views from the septum to the lateral wall endothelium at their widest point just above the mitral valve and tricuspid valve annulus. The prognostic value of this easily measurable echocardiographic parameter was independent of patient history and clinical data. Multivariate analysis showed that the independent predictors of in-hospital mortality included systolic BP $<90 \mathrm{~mm} \mathrm{Hg}$ (odds ratio [OR], 10.73; $\mathrm{p}<0.0001)$, history of left heart failure (OR, 8.99; $\mathrm{p}<0.0001)$, and RV/LV ratio > 0.9 (OR, 2.66; $\mathrm{p}<0.01)$.

\subsubsection{Echocardiographic RV hypokinesis}

Moderate or severe RV free-wall hypokinesis may be accompanied by relatively normal contraction and "sparing" of the RV apex, a phenomenon called the McConnell sign (McConnell et al., 1996). In patients with PE, the McConnell sign had a sensitivity of $77 \%$, a specificity of $94 \%$, a positive predictive value of $71 \%$, and a negative predictive value of $96 \%$. This sign appeared useful in distinguishing between RV dysfunction due to PE and dysfunction due to other conditions, such as primary pulmonary hypertension. For patients with RV hypokinesis due to acute PE, the excursion diminished markedly when measured in the middle of the RV free wall. However, the excursion improved progressively when segments closer to the apex were measured. This pattern of regional RV dysfunction appeared highly specific for acute PE; in patients with RV dysfunction due to primary pulmonary hypertension, RV hypokinesis was not improved when apical segments were assessed. 

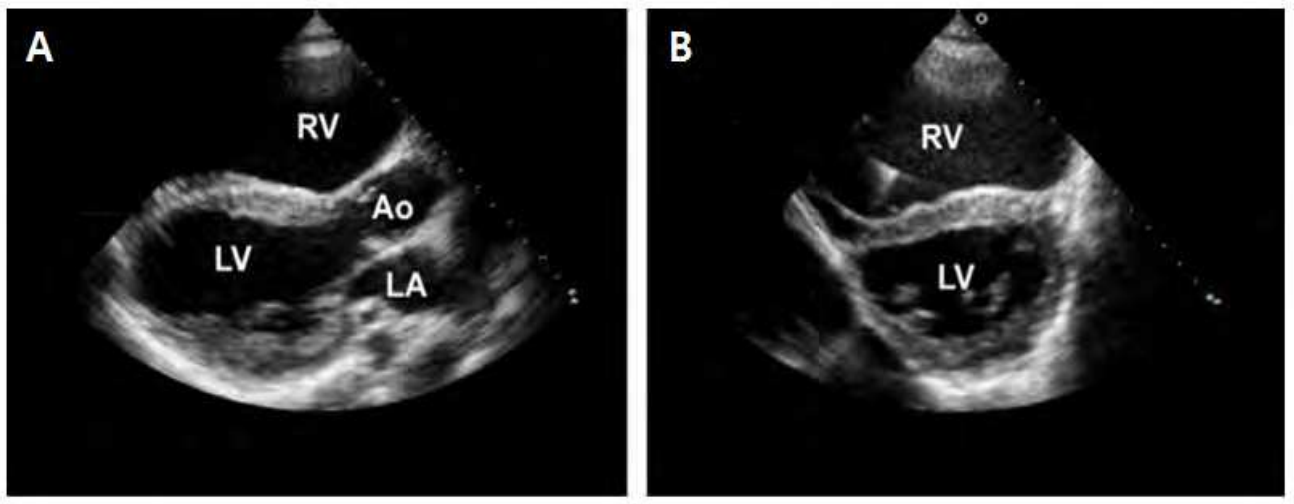

RV: right ventricle; LV: left ventricle; Ao: aorta; LA: left atrium

Fig. 1. Echocardiographic findings of pulmonary embolism in the parasternal long-axis (A) and short-axis (B) views.

\begin{tabular}{ll}
\hline Abnormal Finding & Description \\
\hline $\begin{array}{l}\text { Right ventricular dilatation } \\
\begin{array}{l}\text { Septal flattening and } \\
\text { paradoxical septal motion }\end{array}\end{array}$ & $\begin{array}{l}\text { The ratio of the right ventricular end-diastolic area to left } \\
\text { ventricular end-diastolic area exceeds the upper limit of } \\
\text { nopical four-chamber views) }\end{array}$ \\
$\begin{array}{l}\text { Reduced respiratory } \\
\text { variability of the dilated } \\
\text { inferior vena cava }\end{array}$ & $\begin{array}{l}\text { Subcostal view, diameter }>2 \text { cm with }<50 \% \text { respiratory } \\
\text { variability; indirect sign of increased central venous pressure }\end{array}$ \\
$\begin{array}{l}\text { Pulmonary artery dilation } \\
\text { Tricuspid regurgitation jet } \\
\text { velocity }>2.6 \text { m/s }\end{array}$ & $\begin{array}{l}\text { Main pulmonary artery }>2.5 \text { cm on parasternal short-axis } \\
\text { views; indirect sign of pulmonary hypertension }\end{array}$ \\
$\begin{array}{l}\text { Right ventricular regional } \\
\text { systolic wall motion } \\
\text { abnormalities }\end{array}$ & Direct evidence of pulmonary hypertension \\
\hline
\end{tabular}

Table 1. Abnormal echocardiographic findings in patients with pulmonary embolism

\section{Computed tomography assessment of right ventricular dysfunction}

Contrast-enhanced pulmonary CT angiography is increasingly used for first-line imaging in patients suspected of PE. This method allows the direct visualization of emboli, as well as providing information regarding the status of the right heart. Several methods have been suggested for the quantitative assessment of RV dysfunction by CT. 


\subsection{Computed tomography findings of right ventricular dysfunction 3.1.1 RV dilation (RV/LV ratio)}

Similar to echocardiography, contrast-enhanced CT allows assessment of the right-to-left ventricular ratio. RV and LV diameters are assessed on each single image at the plane of maximal visualization of the ventricular cavities, usually at the mitral valve plane for LV and the tricuspid valve level for RV, between the inner surface endocardial border of the free wall and the surface of the interventricular septum (Fig. 2).

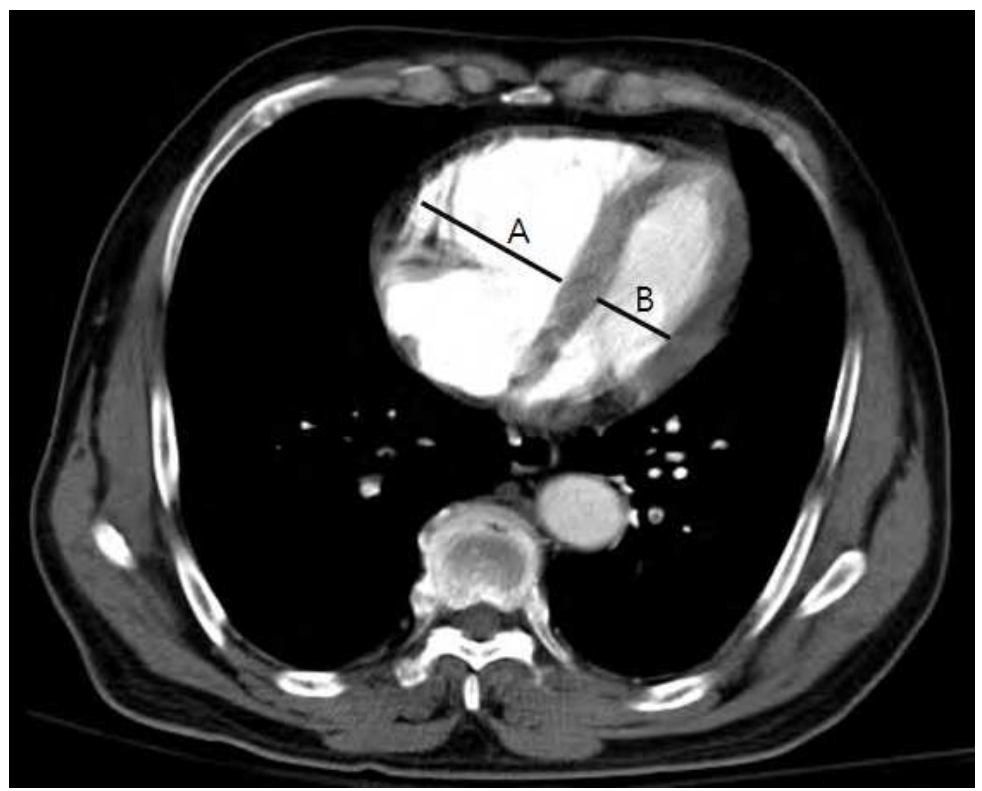

Fig. 2. Transverse contrast-enhanced CT scan showing maximum minor axis measurements of the right ventricle $(\mathrm{A})$ and left ventricle $(\mathrm{B}) . \mathrm{RV} / \mathrm{LV}$ ratio $=2$

The $\mathrm{RV} / \mathrm{LV}$ minor axis ratio is widely accepted as a measure of $\mathrm{RV}$ dilatation on $\mathrm{CT}$, however, the cut-off values of $\mathrm{RV} / \mathrm{LV}$ ratio used for RV dysfunction vary among reports. Ghuysen et al suggested an RV/LV ratio $>1.5$ indicates a severe episode of PE (Ghuysen et al., 2005), Araoz et al suggested an RV/LV ratio $>1$ was associated with a 3.6-fold increased risk of admission to the intensive care unit (Araoz et al., 2003), and in another study, the same threshold was shown to be a significant risk factor for mortality within 3 months, with an $\mathrm{RV} / \mathrm{LV}$ ratio $\leq 1.0$ having a PPV of $10.1 \%$ (95\% CI: $2.9 \%, 17.4 \%)$ and an NPV of $100 \%$ (95\% CI: $94.3 \%, 100 \%$ ) for an uneventful outcome (van der Meer et al., 2005). An RV/LV ratio $>0.9$ on reconstructed CT four-chamber views has been associated with a poorer prognosis in patients with PE (Schoepf et al., 2004), with an NPV of $92.3 \%$ and a PPV of $15.6 \%$ for 30-day mortality, and a hazard ratio for predicting 30-day mortality of 5.17 (95\% CI, 1.63 - 16.35; $\mathrm{P}=0.005)$.

Concerns have arisen regarding whether non-gated CT may be inaccurate in measuring ventricular chamber size because the images are acquired in different phases of the cardiac cycle. However ECG-gated CT scan is not always available, and is time-consuming. Thus, a ECG-gated CT scan is impractical in an emergency situation. In addition, recent findings 
have indicated that the benefits from a separate ECG-gated CT scan for the evaluation of RV ventricular diameter are minimal and do not justify its routine clinical use instead of the standard measurements of the minor axis (Lu et al., 2009).

Although most studies have indicated that $\mathrm{CT}$ assessments of RV dilatation contribute to the risk stratification of patients with $\mathrm{PE}$, two recent meta-analyses have found that CT findings of RV dilatation have limited prognostic importance for mortality among patients with nonhigh-risk PE (Coutance et al., 2011; Sanchez et al., 2008), and that the greatest value of this method appears to be the identification of low-risk patients based on the lack of RV dilatation. These analyses suggested that measurements made on the four-chamber view are more reliable than traditional measurements made on the minor axis. However, most of these studies were of retrospective design and in small numbers of patients with generally undefined clinical presentations. Hence, any conclusions about the usefulness of this marker must be treated with some caution, although future large clinical studies and standardized definitions of RV dilatation will be required in this patient subset.

\subsubsection{Interventricular septal straightening/bowing}

If $\mathrm{RV}$ afterload suddenly increases, the interventricular septum, which normally bows toward the RV, may shift toward the LV because of its confinement within the pericardium. This phenomenon is readily visible on helical CT pulmonary angiography as straightening or bowing of the interventricular septum.

Leftward bowing of the interventricular septum on CT has been related to severe PA obstruction (Fig. 3). This bowing was found to strongly predict admission to the intensive care unit for PE, but was not associated with in-hospital mortality (Araoz et al., 2003). Thus, this sign is likely not an indicator of outcome and is not specific for PE (van der Meer et al., 2005). This bowing has also been observed in patients with chronic pulmonary artery hypertension, although, in the latter condition, the RV wall is usually thickened $(>6 \mathrm{~mm})$, whereas, in acute PE, the RV wall thickness is usually normal.

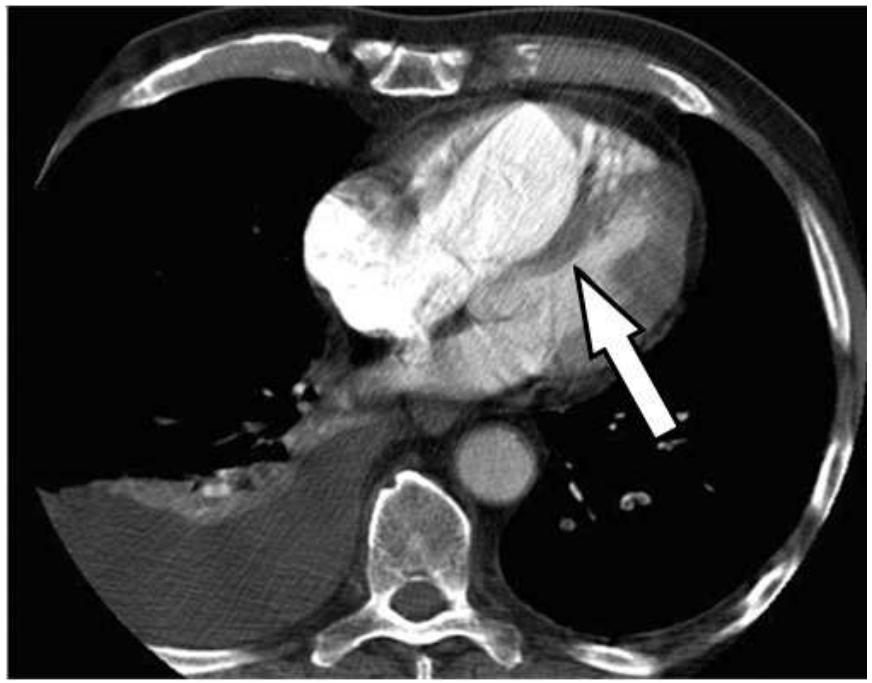

Fig. 3. Ventricular septal bowing (arrow) into the left ventricular lumen 


\subsubsection{Obstruction index}

The PA obstruction index, or the percentage of vascular obstruction of the pulmonary arterial tree caused by PE, may be calculated as $\Sigma(\mathrm{n} \times \mathrm{d})$ expressed as percentage vascular obstruction $([\Sigma(\mathrm{n} \times \mathrm{d}) / 40] \times 100)$, where $\mathrm{n}$ is the value of the proximal clot site that equals the number of segmental branches arising distally, and $d$ is the degree of obstruction, with partial obstruction scored as 1 and complete obstruction as 2. Values for $\mathrm{n}$ range from a minimum of 1 (obstruction of one segment) to a maximum of 20 (obstruction of both right and left pulmonary arteries) (Qanadli et al., 2001). With this scoring system, the maximum obstruction score is 40 (thrombus completely obstructing the pulmonary trunk), which corresponds to a $100 \%$ obstruction index. Using a cutoff of $60 \%, 83 \%$ of the patients with an index $>60 \%$ died, whereas $98 \%$ of patients with a lower index remained alive $(\mathrm{Wu}$ et al., 2004). Patients with an obstruction index $\geq 40 \%$ were found to be at an 11.2 -fold (95\% CI: 1.3 , 93.6) increased risk of dying from PE (van der Meer et al., 2005). However this index may not be practical for routine application without the aid of radiologists.

Another obstruction index, the pulmonary embolism severity index (PESI), was developed to estimate 30-day mortality in patients with acute PE. This index has also been used to identify patients with a low mortality risk who may be suitable for outpatient management of acute PE (Aujesky et al., 2007). The PESI contains 11 differently weighted baseline clinical parameters and is relatively complicated to administer and score. A simplified version of the PESI (sPESI) was therefore developed for ease of application. The sPESI showed similar prognostic accuracy and clinical utility as the PESI, although its use made it easier to identify patients at low-risk of adverse outcomes (Jimenez et al., 2010) (Table 2).
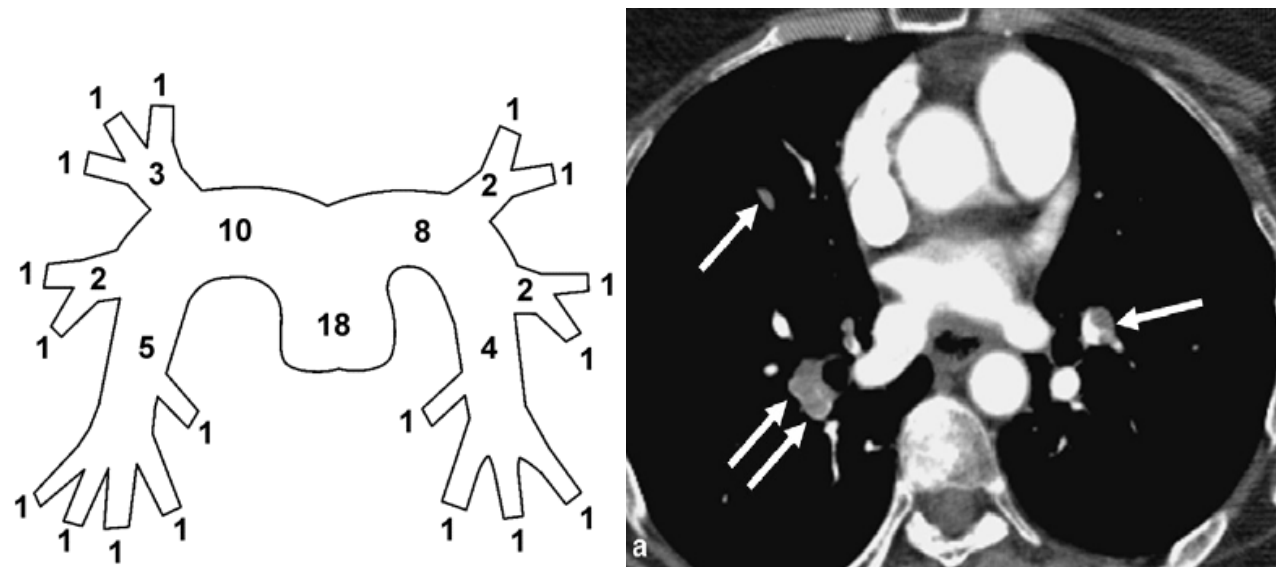

Fig. 4. Transverse contrast-enhanced chest computed tomographic scan showing pulmonary emboli (arrows) in both main pulmonary arteries (PAs). This patient had a PA obstruction index of $55 \%$

\subsubsection{Pulmonary artery diameter measurement}

A pulmonary artery (PA) diameter greater than $30 \mathrm{~mm}$ indicates a PA pressure greater than $20 \mathrm{mmHg}$ (Kuriyama et al., 1984). Moreover, the diameter of the central PA has been significantly correlated with the severity of PE (Collomb et al., 2003). In other studies, however, the diameter of the main PA and the ratio of the diameters of the main PA and the 


\begin{tabular}{lll}
\hline & \multicolumn{2}{c}{ Score } \\
\cline { 2 - 3 } Variable & PESI a & APESI $\mathbf{~}$ \\
\hline Age $>80 \mathrm{y}$ & +10 & 1 \\
Male sex & +30 & 1 \\
History of cancer & +10 & $1 \mathrm{c}$ \\
History of heart failure & +10 & 1 \\
History of chronic lung disease & +20 & 1 \\
Pulse $\geq 110$ beats $/$ min & +30 & \\
Systolic blood pressure $<100 \mathrm{mmHg}$ & +20 & \\
Respiratory rate $\geq 30$ breaths $/ \mathrm{min}$ & +20 & 1 \\
Temperature $<36^{\circ} \mathrm{C}$ & +60 & \\
Altered mental status & +20 & \\
SaO2 $<90 \%$ &
\end{tabular}

a The total point score for each patient is calculated as the sum the patient's age in years and the points for each predictor when present.

Scores corresponding to risk classes include: 65 or less, class I; 66 to 85, class II; 86 to 105, class III; 106 to 125 , class IV; and more than 125 , class V. Patients in risk classes I and II are defined as being at low risk. bThe total point score for each patient is calculated as the sum of the points. Scores correspond to the following risk classes: 0 , low risk; 1 or more, high risk.

c The variables were combined into a single category of chronic cardiopulmonary disease.

Table 2. Original and simplified pulmonary embolism severity index (PESI)

aorta were not indicators of mortality or severity of acute PE (Araoz et al., 2003; van der Meer et al., 2005).

\subsubsection{Saddle pulmonary embolism}

Saddle PE is defined as a visible thromboembolus stradding the bifurcation of the main PA (Fig. 5). Saddle PE occurs at frequency of (5.2\%) in all patients with PE (Pruszczyk et al., 2003). Such proximal thrombus may be regarded unstable, large clot burden in the PA, and "in-transit" embolus, which can fragment spontaneously or secondary to treatment and obstruct multiple, distal pulmonary arteries (Pruszczyk et al., 2003).

Debate has been going on regarding the size of the clot and prognosis. Some studies suggest that simple distinction of saddle versus non-saddle PE by CT findings was associated with death within 1 year (OR 7.4, 95\% CI 1.7-31.5) and may provide a straight forward method for risk stratification (Yusuf et al., 2010). Whereas other studies found that saddle PE was not associated with mortality rate and may not necessitate aggressive medical management (Ryu et al., 2007; Musani, 2010). Therefore the prognosis value of saddle PE is not well established. 


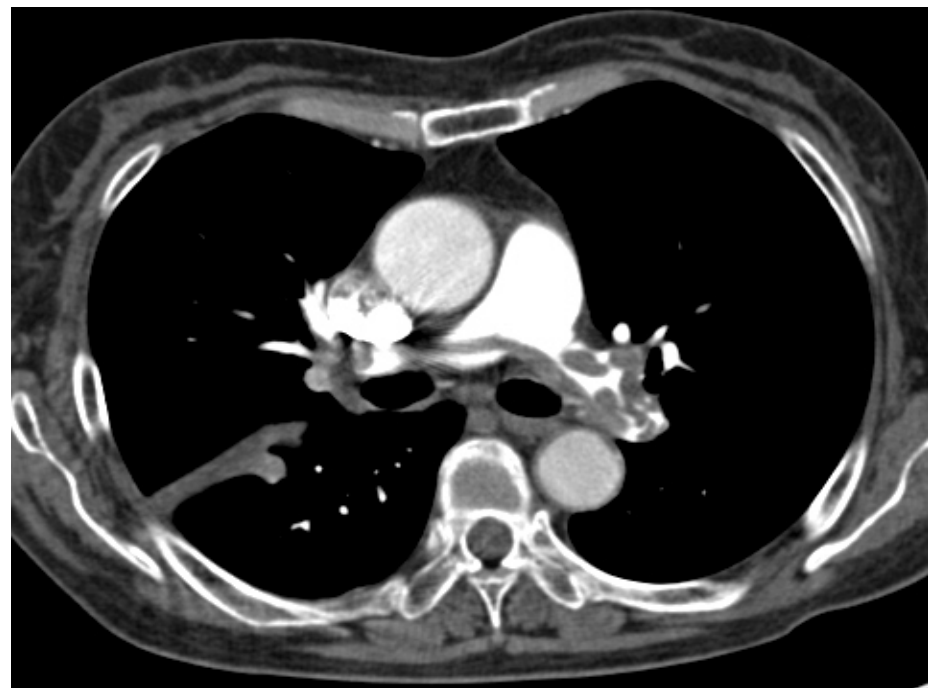

Fig. 5. Saddle pulmonary embolism.

\section{Dual E CT}

Physiologic changes in patients with acute PE, such as RV overload, may be more closely related to the extent of the pulmonary perfusion defect than to the burden of intravascular emboli. Several studies have reported that the extent of the pulmonary perfusion defect, as assessed by perfusion scintigraphy or SPECT, is an important risk factor for recurrence of pulmonary embolism and RV dysfunction (Wolfe et al., 1994; Palla et al., 2010). However, CT angiography has shown better performance than perfusion scintigraphy or SPECT in the initial diagnosis of pulmonary embolism, since the former has several advantages, including high spatial resolution, rapid scanning time and easy availability.

Recent advances in CT technology have included dual-energy CT (DECT), using two tubes (dual-source $\mathrm{CT}$ ) or a single tube with a rapid $\mathrm{kVp}$ switching technique. As iodine has unique spectral properties and X-ray absorption characteristics at higher and lower photon energies (e.g., $140-\mathrm{kVp}$ and $80-\mathrm{kVp}$ ), iodine map images can be generated using DECT angiography (DECTA). These images may represent the regional perfusion status of lung parenchyma and showed good correlation with scintigraphic findings in patients with PE (Pontana et al., 2008; Thieme et al., 2008). Weighted-average $120-\mathrm{kVp}$ equivalent CT angiography obtained from DECTA can be used for the direct visualization of a thromboembolism and for the evaluation of CT signs of RV dysfunction, similar to standard CT angiography. That is, information about regional lung perfusion status, as well as the burden of intravascular emboli and right-sided heart failure, can be evaluated by single scanning DECT.

$\mathrm{RV}$ dysfunction is predictive of a poor prognosis in patients with acute PE. On CT angiography images, $\mathrm{RV} / \mathrm{LV}$ diameter ratio is a reliable marker of $\mathrm{RV}$ dysfunction, with higher RV/LV diameter ratios related to poor clinical outcomes (Quiroz et al., 2004; Schoepf et al., 2004; van der Meer et al., 2005). Furthermore, the extent of perfusion defect on DECTA has been correlated with RV/LV diameter ratio (Zhang et al., 2009; Chae et al., 2010; Bauer 
et al., 2011). A novel dual energy perfusion defect score has been proposed, in which the degree of lung perfusion in each segment is graded on a 3-point scale $(0$, normal perfusion; 1 , moderately reduced perfusion, 2, profoundly reduced or absent perfusion), with the perfusion defect score calculated as $\sum(n \cdot d) / 40 \times 100$, where $n$ is the number of segments and $\mathrm{d}$ is the degree of the perfusion defect (Chae et al., 2010). The perfusion defect score has shown good correlation with RV/LV diameter ratio $(r=0.69, p<0.001)$. In addition, the numbers of lobes with pulmonary perfusion defects on iodine images of DECTA correlated well with RV/LV diameter ratio $(r=0.66, p<0.05)$, whereas the number of lobes with PE on CT angiography did not $(p>0.05)$. Quantification of the area of pulmonary perfusion defect on iodine images showed that an pulmonary perfusion defect over $215.4 \mathrm{ml}$ or a relative volume over $9.9 \%$ was related to an RV/LV diameter ratio > 1 (Bauer et al., 2011). These results therefore indicate that pulmonary perfusion defect size may be a surrogate marker for RV dysfunction (Fig. 6, Fig. 7). Readmission and death due to PE were observed only in patients with a relative perfusion defect size $>5 \%$ of total lung volume, but not in any patient with a relative perfusion defect $<5 \%$ (Bauer, Frellesen et al. 2011). Patients with a relative perfusion defect $>5 \%$ also showed lower median survival with increased relative hazard ratio for death than those with a relative perfusion defect $<5 \%$. These results indicate that pulmonary perfusion defect size may be prognostic in patients with PE.

The status of the pulmonary microvasculature is important in evaluating disease severity and prognosis in patients with PE. Although ventilation/perfusion scintigraphy was used to assess the pulmonary nomenclature, multi-detector CT angiography has replaced scintigraphy in the evaluation of these patients, since CT has higher spatial resolution and shorter acquisition time. Recently developed advanced CT techniques, including DECT, permits the evaluation of pulmonary perfusion status without significant additional radiation dose. Therefore, DECTA may become a leading imaging tool, both for detecting emboli and for risk stratification regarding of regional pulmonary perfusion status in patients with PE.

\section{The role of chest computed tomography as an alternative to echocardiography}

Retrospective studies have shown that multidetector chest CT and echocardiography yield similar prognostic data (Sanchez et al., 2008). While CT provides information on RV dilatation only, echocardiography also provides some information on contractility, e.g., septal or RV hypo- or dyskinesia. However, echocardiography is not always available in emergency settings and has limitations, including poor RV image quality and lack of a universal definition of RV dysfunction. Indeed, this method has limited sensitivity and negative findings on echocardiography do not exclude a diagnosis of PE (Miniati et al., 2001). In contrast, CT pulmonary angiography allows direct visualization of clots, as well as providing information on the status of the right heart and other adjacent organs. This tool is available around the clock at most institutions and has become the first-line test for patients suspected of having PE. PE may be diagnosed and its risk stratified at the same time. Of course, CT has several limitations, including an inability to assess RV function in real time and the lack of universally accepted criteria. Confirmation of these findings in further, prospective studies may make multidetector-row chest $\mathrm{CT}$ a reasonable alternative to echocardiography for diagnosing RV dysfunction. Imaging techniques are constantly being improved in the 
Risk Stratification of Submassive Pulmonary Embolism:

diagnostic workup of patients with suspected PE. Thus, CT has the potential to become the link between diagnostic and risk stratification strategies in this setting.

(a)

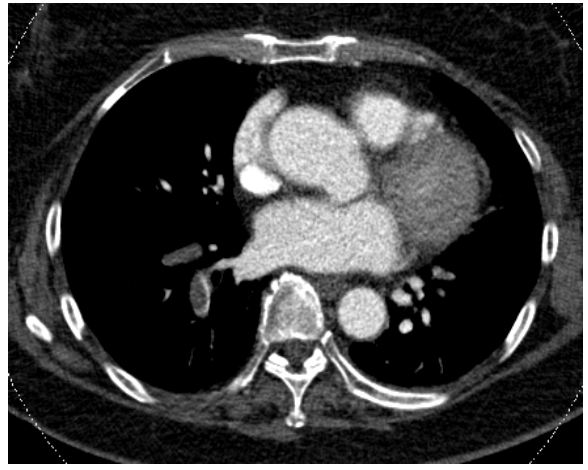

(b)

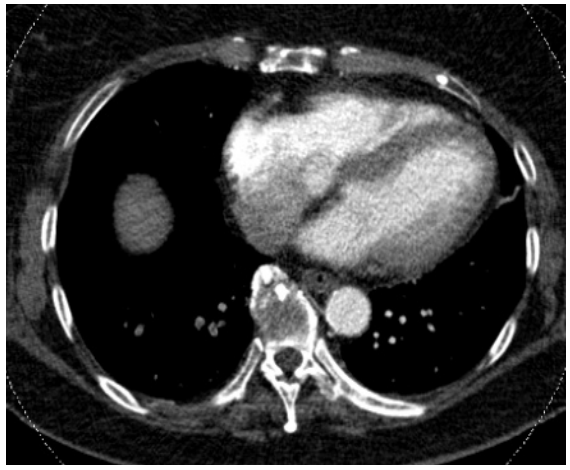

(d)

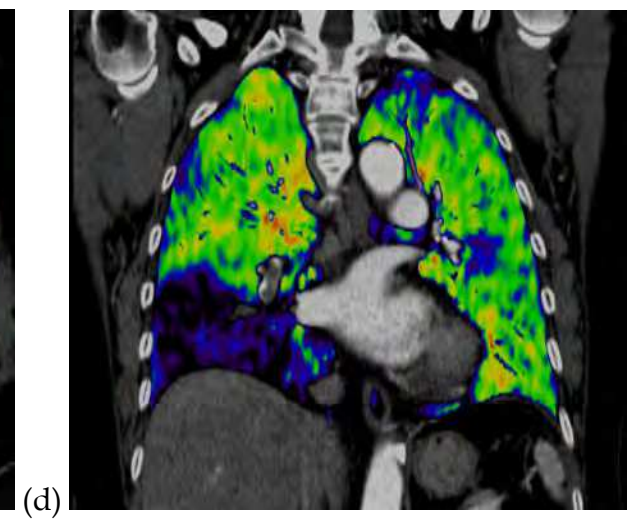

(c)

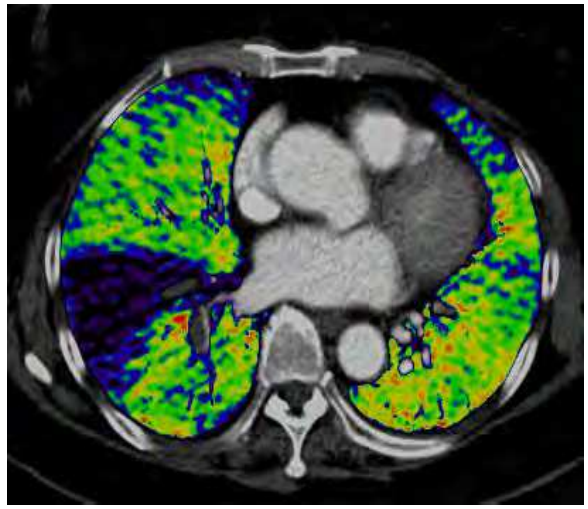

Fig. 6. Pulmonary embolism without right ventricular dysfunction. (a) Dual-energy CT angiography (DECTA) shows filling defect in segmental branches of pulmonary arteries in right lower lobe. (b) DECTA shows normal ranged diameters of ventricles (RV/LV ratio < 1). (c \& d) Lung iodine images show wedge shaped pulmonary perfusion defect in right lower lobe lateral basal segment where emboli completely occludes pulmonary artery. However, the posterior basal segment of right lower lobe shows normal perfusion status, because emboli partly occlude corresponding pulmonary artery. The relative volume of pulmonary perfusion defect was $8.3 \%$ and perfusion defect score was 10 . 
(a)

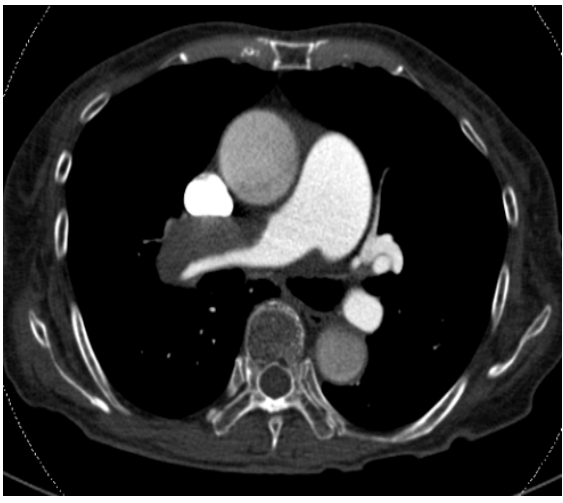

(c)

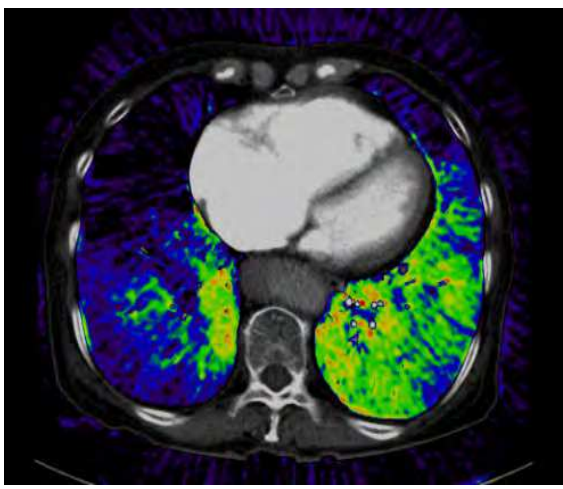

(d)

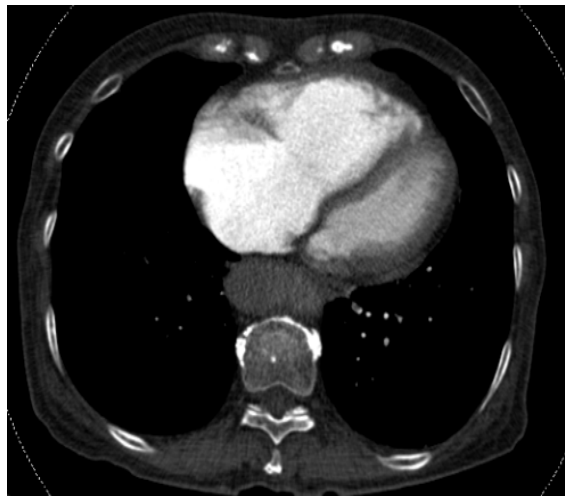

(b)

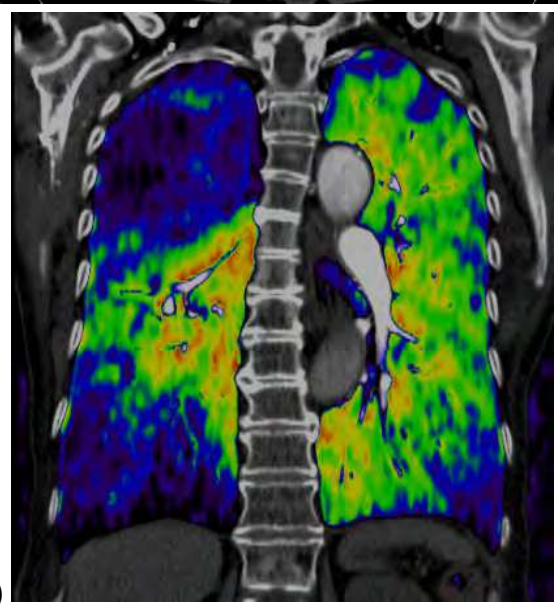

Fig. 7. Pulmonary embolism with right ventricular dysfunction. (a) Dual-energy CT angiography (DECTA) shows filling defect in right main pulmonary artery. (b) DECTA shows enlarged right ventricle $(\mathrm{RV} / \mathrm{LV}$ ratio $>1)$. ( $\mathrm{c} \& \mathrm{~d})$ Lung iodine images show perfusion defect in right lung except superior segment and posterior basal segment of right lower lobe. Multifocal wedge shaped perfusion defect in also noted in subpleural portion of left lung. The relative volume of pulmonary perfusion defect was $47.8 \%$ and perfusion defect score was 52.5 .

\section{Conclusion}

This chapter focused on the prognostic value of RV dysfunction as measured by chest CT in patients with hemodynamically stable PE. Although echocardiographic assessment of RV dysfunction is a generally accepted imaging modality, the lack of a clear echocardiographic definition of RV dysfunction, and the poor RV images, reduces its diagnostic capabilities. $\mathrm{RV}$ dysfunction assessed by $\mathrm{CT}$, including $\mathrm{RV}$ enlargement, RV/LV ratio, interventricular septal bowing, pulmonary obstruction score, and pulmonary perfusion defect have been associated with poor patient outcomes. Risk stratification of patients with stable PE based on chest $\mathrm{CT}$ findings may comparable in results to echocardiography and may be useful. 


\section{References}

Araoz, P. A., Gotway, M. B., Trowbridge, R. L., Bailey, R. A., Auerbach, A. D., Reddy, G. P., et al. (2003). Helical CT pulmonary angiography predictors of in-hospital morbidity and mortality in patients with acute pulmonary embolism, J Thorac Imaging Vol. 18 (4): 207-216.

Aujesky, D., Perrier, A., Roy, P. M., Stone, R. A., Cornuz, J., Meyer, G., et al. (2007). Validation of a clinical prognostic model to identify low-risk patients with pulmonary embolism, J Intern Med Vol. 261 (6): 597-604.

Bauer, R. W., Frellesen, C., Renker, M., Schell, B., Lehnert, T, Ackermann, H., et al. (2011). Dual energy CT pulmonary blood volume assessment in acute pulmonary embolism - correlation with D-dimer level, right heart strain and clinical outcome, Eur Radiol Vol. 21 (9): 1914-1921.

Chae, E. J., Seo, J. B., Jang, Y. M., Krauss, B., Lee, C. W., Lee, H. J., et al. (2010). Dual-energy $\mathrm{CT}$ for assessment of the severity of acute pulmonary embolism: pulmonary perfusion defect score compared with $\mathrm{CT}$ angiographic obstruction score and right ventricular/left ventricular diameter ratio. AJR Am J Roentgenol Vol. 194 (3): 604610.

Collomb, D., Paramelle, P. J., Calaque, O., Bosson, J. L., Vanzetto, G., Barnoud, D., et al. (2003). Severity assessment of acute pulmonary embolism: evaluation using helical CT, Eur Radiol Vol. 13 (7): 1508-1514.

Coutance, G., Cauderlier, E., Ehtisham, J., Hamon, M., \& Hamon, M. (2011). The prognostic value of markers of right ventricular dysfunction in pulmonary embolism: a metaanalysis, Crit Care Vol. 15 (2): R103.

Fremont, B., Pacouret, G., Jacobi, D., Puglisi, R., Charbonnier, B., \& de Labriolle, A. (2008). Prognostic value of echocardiographic right/left ventricular end-diastolic diameter ratio in patients with acute pulmonary embolism: results from a monocenter registry of 1,416 patients, Chest Vol. 133 (2): 358-362.

Ghaye, B., Ghuysen, A., Willems, V., Lambermont, B., Gerard, P., D'Orio, V., et al. (2006). Severe pulmonary embolism:pulmonary artery clot load scores and cardiovascular parameters as predictors of mortality, Radiology Vol. 239 (3): 884-891.

Ghuysen, A., Ghaye, B., Willems, V., Lambermont, B., Gerard, P., Dondelinger, R. F., et al. (2005). Computed tomographic pulmonary angiography and prognostic significance in patients with acute pulmonary embolism, Thorax Vol. 60 (11): 956961.

Goldhaber, S. Z., \& Elliott, C. G. (2003). Acute pulmonary embolism: part II: risk stratification, treatment, and prevention, Circulation Vol. 108 (23): 2834-2838.

Goldhaber, S. Z., Visani, L., \& De Rosa, M. (1999). Acute pulmonary embolism: clinical outcomes in the International Cooperative Pulmonary Embolism Registry (ICOPER), Lancet Vol. 353 (9162): 1386-1389.

Goldhaber, S. Z. (2002). Echocardiography in the management of pulmonary embolism, Ann Intern Med Vol. 136 (9): 691-700

Grifoni, S., Olivotto, I., Cecchini, P., Pieralli, F., Camaiti, A., Santoro, G., et al. (2000). Shortterm clinical outcome of patients with acute pulmonary embolism, normal blood 
pressure, and echocardiographic right ventricular dysfunction, Circulation Vol. 101 (24): 2817-2822.

Jimenez D., Escobar C., Marti D., Diaz G., Vidal R., Taboada D., et al. (2007). Prognostic value of transthoracic echocardiography in hemodynamically stable patients with acute symptomatic pulmonary embolism, Arch Bronconeumol Vol. 43 (9): 490494

Jimenez, D., Aujesky, D., Moores, L., Gomez, V., Lobo, J. L., Uresandi, F., et al. (2010). Simplification of the pulmonary embolism severity index for prognostication in patients with acute symptomatic pulmonary embolism, Arch Intern Med Vol. 170 (15): 1383-1389.

Konstantinides, S. (2005). Pulmonary embolism: impact of right ventricular dysfunction, Curr Opin Cardiol Vol. 20 (6): 496-501.

Konstantinides, S. V. (2008). Massive pulmonary embolism: what level of aggression?, Semin Respir Crit Care Med Vol. 29 (1): 47-55.

Kreit, J. W. (2004). The impact of right ventricular dysfunction on the prognosis and therapy of normotensive patients with pulmonary embolism, Chest Vol. 125 (4): 1539-1545.

Kucher, N., Rossi, E., De Rosa, M., \& Goldhaber, S. Z. (2005). Prognostic role of echocardiography among patients with acute pulmonary embolism and a systolic arterial pressure of $90 \mathrm{~mm} \mathrm{Hg}$ or higher, Arch Intern Med Vol. 165 (15): 1777-1781.

Kuriyama, K., Gamsu, G., Stern, R. G., Cann, C. E., Herfkens, R. J., \& Brundage, B. H. (1984). CT-determined pulmonary artery diameters in predicting pulmonary hypertension, Invest Radiol Vol. 19 (1): 16-22.

Lu, M. T., Cai, T., Ersoy, H., Whitmore, A. G., Levit, N. A., Goldhaber, S. Z., et al. (2009). Comparison of ECG-gated versus non-gated CT ventricular measurements in thirty patients with acute pulmonary embolism, Int J Cardiovasc Imaging Vol. 25 (1): 101107.

Musani M.H. (2010). Asymptomatic saddle pulmonary embolism: case report and literature review, Clin Appl Thromb Hemost.

McConnell M.V., Solomon S.D., Rayan M.E., Come P.C., Goldhaber S.Z., Lee R.T. (1996). Regional right ventricular dysfunction detected by echocardiography in acute pulmonary embolism, Am J Cardiol. Vol. 78 (4): 469-73.

Miniati, M., Monti, S., Pratali, L., Di Ricco, G., Marini, C., Formichi, B., et al. (2001). Value of transthoracic echocardiography in the diagnosis of pulmonary embolism: results of a prospective study in unselected patients, Am J Med Vol. 110 (7): 528-535.

Palla, A., Ribas, C., Rossi, G., Pepe, P., Marconi, L. \& Prandoni, P. (2010). The clinical course of pulmonary embolism patients anticoagulated for 1 year: results of a prospective, observational, cohort study. J Thromb Haemost Vol. 8 (1): 68-74.

Pontana, F., Faivre, J. B., Remy-Jardin, M., Flohr, T., Schmidt, B., Tacelli N., et al. (2008). Lung perfusion with dual-energy multidetector-row CT (MDCT): feasibility for the evaluation of acute pulmonary embolism in 117 consecutive patients. Acad Radiol Vol. 15 (12): 1494-1504.

Pruszczyk P., Pacho R., Ciurzynski M., Burakowska B., Tomkowski W., Bochowicz A., et al., et al. (2003). Short term clinical outcome of acute saddle pulmonary embolism, Heart Vol. 89 (3): 335-336. 
Qanadli, S. D., El Hajjam, M., Vieillard-Baron, A., Joseph, T., Mesurolle, B., Oliva, V. L., et al. (2001). New CT index to quantify arterial obstruction in pulmonary embolism: comparison with angiographic index and echocardiography, AJR Am J Roentgenol Vol. 176 (6): 1415-1420.

Quiroz, R., Kucher, N., Schoepf, U. J., Kipfmueller, F., Solomon, S.D., Costello, P., et al. (2004). Right ventricular enlargement on chest computed tomography: prognostic role in acute pulmonary embolism. Circulation Vol. 109 (20): 2401-2404.

Ribeiro, A., Lindmarker, P., Juhlin-Dannfelt, A., Johnsson, H., \& Jorfeldt, L. (1997). Echocardiography Doppler in pulmonary embolism: right ventricular dysfunction as a predictor of mortality rate, Am Heart J Vol. 134 (3): 479-487.

Ryu J.H., Pellikka P.A., Froehling D.A., Peters S.G., Aughenbaugh G.L. (2007). Saddle pulmonary embolism diagnosed by CT angiography: frequency, clinical features and outcome, Respir Med Vol. 101 (7): 1537-1542.

Sanchez, O., Trinquart, L., Colombet, I., Durieux, P., Huisman, M. V., Chatellier, G., et al. (2008). Prognostic value of right ventricular dysfunction in patients with haemodynamically stable pulmonary embolism: a systematic review, Eur Heart J Vol. 29 (12): 1569-1577.

Schoepf, U. J., \& Costello, P. (2004). CT angiography for diagnosis of pulmonary embolism: state of the art, Radiology Vol. 230 (2): 329-337.

Schoepf, U. J., Kucher, N., Kipfmueller, F., Quiroz, R., Costello, P., \& Goldhaber, S. Z. (2004). Right ventricular enlargement on chest computed tomography: a predictor of early death in acute pulmonary embolism, Circulation Vol. 110 (20): 3276-3280.

ten Wolde, M., Sohne, M., Quak, E., Mac Gillavry, M. R., \& Buller, H. R. (2004). Prognostic value of echocardiographically assessed right ventricular dysfunction in patients with pulmonary embolism, Arch Intern Med Vol. 164 (15): 1685-1689.

Thieme, S. F., Becker, C. R., Hacker, M., Nikolaou, K., Reiser, M. F., \& Johnson, T. R. (2008). Dual energy CT for the assessment of lung perfusion--correlation to scintigraphy. Eur J Radiol Vol. 68 (3): 369-374.

Torbicki, A., Galie, N., Covezzoli, A., Rossi, E., De Rosa, M., \& Goldhaber, S. Z. (2003). Right heart thrombi in pulmonary embolism: results from the International Cooperative Pulmonary Embolism Registry, J Am Coll Cardiol Vol. 41 (12): 2245-2251.

Torbicki, A., Perrier, A., Konstantinides, S., Agnelli, G., Galie, N., Pruszczyk, P., et al. (2008). Guidelines on the diagnosis and management of acute pulmonary embolism: the Task Force for the Diagnosis and Management of Acute Pulmonary Embolism of the European Society of Cardiology (ESC), Eur Heart J Vol. 29 (18): 2276-2315.

van der Meer, R. W., Pattynama, P. M., van Strijen, M. J., van den Berg-Huijsmans, A. A., Hartmann, I. J., Putter, H., et al. (2005). Right ventricular dysfunction and pulmonary obstruction index at helical CT: prediction of clinical outcome during 3month follow-up in patients with acute pulmonary embolism, Radiology Vol. 235 (3): 798-803.

Wu, A. S., Pezzullo, J. A., Cronan, J. J., Hou, D. D., \& Mayo-Smith, W. W. (2004). CT pulmonary angiography: quantification of pulmonary embolus as a predictor of patient outcome--initial experience, Radiology Vol. 230 (3): 831-835.

Wolfe, M. W., Lee, R. T., Feldstein, M. L., Parker, J. A., Come, P. C., \& Goldhaber, S. Z. (1994). Prognostic significance of right ventricular hypokinesis and perfusion lung scan defects in pulmonary embolism. Am Heart J Vol. 127 (5): 1371-1375. 
Zhang, L. J., Yang, G. F., Zhao, Y. E., Zhou, C. S., \& Lu, G M. (2009). Detection of pulmonary embolism using dual-energy computed tomography and correlation with cardiovascular measurements: a preliminary study. Acta Radiol Vol. 50 (8): 892-901. 


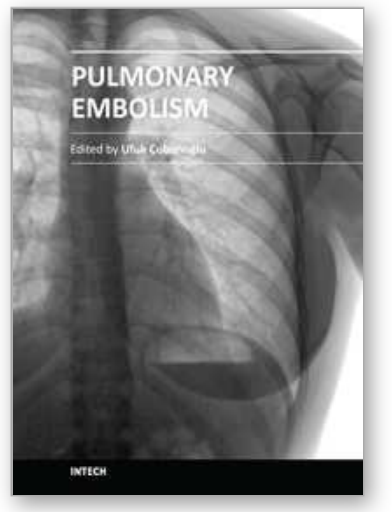

\author{
Pulmonary Embolism \\ Edited by Dr. Ufuk Çobanoğlu
}

ISBN 978-953-51-0233-5

Hard cover, 236 pages

Publisher InTech

Published online 14, March, 2012

Published in print edition March, 2012

Pulmonary embolism is a serious, potentially life-threatening cardiopulmonary disease that occurs due to partial or total obstruction of the pulmonary arterial bed. Recently, new improvement occurred in the diagnosis and treatment of the disease. The aim of this disease is to re-review pulmonary embolism in the light of new developments. In this book, in addition to risk factors causing pulmonary embolus, a guide for systematic approaches to lead the risk stratification for decision making is also presented. In order to provide a maximum length of active life and continuation of functional abilities as the aim of new interventional gerontology, the risk factors causing pulmonary embolus in elderly individuals are evaluated, and the approach to prevention and treatment are defined. The risk of the development of deep vein thrombosis and pulmonary embolism, combined with obesity due to immobility, the disease of this era, irregular and excessive eating, and treatment management are highlighted. Non-thrombotic pulmonary emboli are also covered and an attempt is made to constitute an awareness of this picture that can change the treatment and prognosis of the disease to a considerable extent. In addition to the pathophysiological definition of pulmonary embolus, the priority goal of quick and definitive diagnosis is emphasized, and diagnostic strategies are discussed in the book. A numerical analysis of the vena cava filters, which is a current approach to prevent pulmonary emboli recurrences, is presented in the last chapter.

\title{
How to reference
}

In order to correctly reference this scholarly work, feel free to copy and paste the following:

Won Young Kim, Shin Ahn and Choong Wook Lee (2012). Risk Stratification of Submassive Pulmonary Embolism: The Role of Chest Computed Tomography as an Alternative to Echocardiography, Pulmonary Embolism, Dr. Ufuk Çobanoğlu (Ed.), ISBN: 978-953-51-0233-5, InTech, Available from:

http://www.intechopen.com/books/pulmonary-embolism/risk-stratification-of-submassive-pulmonary-embolismthe-role-of-chest-computed-tomography-as-an-alt

\section{INTECH}

open science | open minds

\section{InTech Europe}

University Campus STeP Ri

Slavka Krautzeka 83/A

51000 Rijeka, Croatia

Phone: +385 (51) 770447

\section{InTech China}

Unit 405, Office Block, Hotel Equatorial Shanghai

No.65, Yan An Road (West), Shanghai, 200040, China

中国上海市延安西路65号上海国际贵都大饭店办公楼405单元

Phone: +86-21-62489820 
Fax: +385 (51) 686166

Fax: +86-21-62489821

www.intechopen.com 
(C) 2012 The Author(s). Licensee IntechOpen. This is an open access article distributed under the terms of the Creative Commons Attribution 3.0 License, which permits unrestricted use, distribution, and reproduction in any medium, provided the original work is properly cited. 